\title{
Estatuto de Museus, Comunicação e Museus de Tribunais Superiores do Judiciário no Brasil
}

\author{
Robson de Goes e Silva' \\ Fernando Oliveira Paulino
}

\section{Resumo}

Este artigo buscou verificar se museus localizados em tribunais superiores (STF, ST), STM, TSE e TST) têm levado em conta ou não as diretrizes previstas pelo Estatuto de Museus, Lei II.904/2009, principalmente no que se refere às atividades ligadas à comunicação, compreendidas como as formas de se fazer conhecer os bens culturais incorporados ou depositados no museu, de acordo com o art. 3 I da referida Lei. Para isso, a pesquisa utilizou a metodologia da Hermenêutica de Profundidade, desenvolvida inicialmente por Thompson (1995). Utilizando alguns artigos da Lei como parâmetro de análise, foi possível, concluir que embora em vigor há nove anos, o Estatuto não tem sido efetivamente cumprido pelas próprias instituições ligadas ao Poder Judiciário.

\section{Palavras-chave}

Museologia; Museus institucionais; Estatuto de Museus; Comunicação em museus; Hermenêutica de Profundidade.

\section{Abstract}

This article sought to verify whether museums located in higher courts (STF, ST), STM,TSE and TST) have been followed or not the guidelines established by the Statute of Museums, Law I I.904/2009, especially about communication matters. This research was guided in accordance to methodology of Depth Hermeneutics, initially developed by Thompson (1995) Using some articles of the Law as a parameter of analysis, it was possible to conclude that although in force for nine years, the Statute has not been effectively complied by the institutions linked to the Judiciary.

\section{Keywords}

Museology; Institutional museums; Statute of Museums; Communication in museums; Depth hermeneutics.

\section{Introdução}

O objetivo do presente trabalho é analisar os cinco museus dos tribunais superiores no Brasil, sendo eles: Supremo Tribunal Federal (STF), Superior Tribunal de Justiça (STJ), Superior Tribunal Militar (STM), Tribunal Superior Eleitoral (TSE) e Tribunal Superior do Trabalho (TST). Busca-se verificar como essas instituições têm levado em conta as diretrizes previstas pelo Estatuto de Museus, Lei II.904/2009, principalmente no que diz respeito às atividades ligadas à comunicação.

Como ponto de partida, é importante frisar que embora a comunicação nos museus possa ser realizada de diferentes formas, o presente artigo faz parte dos resultados de uma pesquisa cujo recorte consiste na compreensão de comunicação em museus segundo o art. 3 I da Lei II.904/2009, que prevê que "ações de comunicação constituem formas de se fazer conhecer os bens culturais incorporados ou depositados no museu, de forma a propiciar o acesso

I Mestre em Comunicação pela Universidade de Brasília.

2 Professor Associado da Faculdade de Comunicação da Universidade de Brasília. 
público" (BRASIL, 2009). Diante disso, foram consideradas principalmente as ações de divulgação realizadas pelos museus estudados e/ou pelas assessorias dos tribunais, de forma que outros aspectos ligados à Comunicação Museológica, como a existência de exposições e projetos educativos, foram contemplados no artigo apenas em caráter de contextualização.

Antes de apresentar os resultados empíricos da análise, foram sistematizados conceitos importantes que fortalecem a metodologia utilizada.

A instituição museu passou por diversas transformações ao longo do tempo, inicialmente abrigavam coleções para uso e fruição particulares e depois passaram a ser instituições abertas ao público, visando a interação social com o patrimônio preservado, conforme pontua Julião:

As mudanças do significado de museu através dos tempos talvez possam ser compreendidas como uma trajetória entre a abertura de coleções privadas à visitação pública, ao surgimento dos museus na acepção moderna, como instituições a serviço do público. (JULIÃO, 2006, p. 29)

O caráter participativo e democrático dos museus passa a constar como prioridade das preocupações dessas instituições principalmente após os resultados da Mesa Redonda de Santiago do Chile (1972), que discutiu as novas ideias no campo museológico (NASCIMENTO JÚNIOR e CHAGAS, 2007, p. 39).

Nesse sentido, são indicados aos museus hoje realizar diferentes formas de interação com o público, pois "não constituem blocos monolíticos imutáveis, são espaços de interação social” (KOPTCKE, 200I, p.24) no qual seus trabalhos internos com o patrimônio material ou imaterial passam a fazer sentido a partir de sua vivência e apropriação pela sociedade.

A compreensão do Conselho Internacional de Museus (ICOM), reitera tal percepção, ao apontar que museu é:

uma instituição sem fins lucrativos, permanente, a serviço da sociedade e de seu desenvolvimento, e aberta ao público, que adquire, conserva, pesquisa, divulga e expõe, para fins de estudo, educação e divertimento, testemunhos materiais do povo e seu meio ambiente. (ICOM, 1986)

Iniciativas como a implementação da Política Nacional de Museus (PNM) lançada em 2003 pelo Ministério da Cultura (MinC) e posteriormente a implementação das Leis II.904/2009, denominada Estatuto de Museus, e I I.906/2009, de criação do Instituto Brasileiro de Museus (Ibram) - autarquia vinculada inicialmente ao então Ministério da Cultura, orientam uma série de ações e procedimentos a serem seguidos pelo setor museológico no Brasil e confere ao Ibram competência de fiscalização.

A PNM insere o Brasil em um conjunto de países que mantêm uma política pública com ações que buscam estimular a apropriação da população brasileira às mais de 3,7 mil instituições museológicas em todo o território nacional . Um dos eixos da PNM intitulado "Democratização e acesso aos bens culturais" busca apoio às ações que tenham por objetivo a difusão do acesso aos museus e o desenvolvimento de ações para sua comunicação.

O Estatuto de Museus, Lei I I.904/2009,“representa um marco regulatório, até então inexistente" (FERNANDES, 20I3, p. 2) que incorpora alguns parâmetros previstos pelo ICOM, na legislação brasileira, como a própria definição 
de museu, que se assemelha ao padrão internacional anteriormente mencionado. Para efeito da lei brasileira, os museus passam a ser compreendidos como:

\begin{abstract}
Instituições sem fins lucrativos que conservam, investigam, comunicam, interpretam e expõem, para fins de preservação, estudo, pesquisa, educação, contemplação e turismo, conjuntos e coleções de valor histórico, artístico, científico, técnico ou de qualquer outra natureza cultural, abertas ao público, a serviço da sociedade e de seu desenvolvimento. (BRASIL, Lei II.904/2009)
\end{abstract}

A lei estabelece também princípios fundamentais que devem pautar o trabalho dos museus, como promoção da cidadania, cumprimento da função social, preservação do patrimônio cultural, acesso e inclusão social, respeito e valorização da diversidade cultural, conforme consta em seu art. $2^{\circ}$. Além disso, o Sistema Brasileiro de Museus, anteriormente instituído pelo Decreto $n^{\circ} 5.264$ de 2004, é incorporado ao Estatuto e tem como uma de suas funções básicas a promoção da interação entre os museus, instituições afins e profissionais ligados ao setor (art. 55 a 6I).

Outro ponto bastante discutido sobre o Estatuto foi a obrigatoriedade de elaboração e implementação de um Plano Museológico em todo museu, considerada ferramenta básica de planejamento estratégico (art. 45 a 47), contendo programas específicos de acordo com cada setor da instituição, dentre eles o de Comunicação, entendida como as formas de se fazer conhecer os bens culturais incorporados ou depositados no museu, de forma a propiciar o acesso público (art. 3I).

De acordo com o art. 67 da Lei II.904/2009 os museus teriam o prazo de cinco anos, contados a partir da publicação da Lei, para adequarem suas estruturas, recursos e ordenamentos ao disposto no Estatuto, sendo que os museus federais já em funcionamento deveriam proceder à adaptação de suas atividades no prazo de dois anos. Dessa forma, a partir de 2014 esperava-se que todos os museus no Brasil estivessem adequado às diretrizes previstas na lei.

Apesar do Estatuto de Museus estabelecer que os museus devam estar a serviço da sociedade e de seu desenvolvimento, ainda há um distanciamento da população com esses espaços, principalmente ao serem considerados fatores como renda familiar e escolaridade, conforme constatado pelo lbram durante pesquisa , na qual foi possível identificar que mais de $70 \%$ da população do Distrito Federal (DF) não frequenta os museus locais.

Diante do contexto referenciado acima, surgiu o interesse de desenvolver pesquisa para verificar se o baixo índice de visitação aos museus locais teria alguma relação com uma possível dificuldade dos museus em se adequarem ao Estatuto de Museus. Para isso, tomou-se como referência a realidade da capital federal e suas características museais.

Segundo o Cadastro Nacional de Museus (CNM) do lbram, existem atualmente $8 \mathrm{I}$ museus no DF, dentre os quais a maioria é vinculada a algum órgão da Administração Pública, ou seja, Brasília é considerada um local com predominância de museus institucionais.

Para a museóloga Célia Corsino "museus institucionais existem para guardar e divulgar uma memória, são uma ferramenta de difusão da marca de uma instituição, servem para contar sua trajetória até o momento atual" (Informação verbal) .

Daniele Pestana (2015) ressalta que museus institucionais podem ser compreendidos como instituições no interior de outras instituições, em que um 
dos aspectos que confere singularidade a esses museus é que estão inseridos em uma outra estrutura cuja atividade fim não é museológica. Por exemplo, o Museu do TCU, objeto de estudo da autora, tem como atividade fim o controle de gastos públicos e não a preservação patrimonial, consequentemente, o museu que ali está inserido ali apresenta características diferentes de outros museus que possuem autonomia administrativa e orçamentária.

A mesma autora pontua que museus institucionais possuem um contexto diferente de trabalho, no qual muitas vezes desenvolvem atividades que buscam produzir uma boa imagem institucional, sem necessariamente se preocupar em problematizar o papel do órgão na sociedade e nem os processos de memória ali condensados.

Tratando-se de museus vinculados ao Poder Judiciário, é importante considerar que se a própria ideia de museu ainda está inserida em uma realidade pouco próxima da maioria da população, quando aliada ao contexto de Justiça tende a fortalecer ainda mais esse distanciamento. Conforme demonstra Nascimento (20I0), em estudo sobre o acesso à justiça:

O acesso ao judiciário se torna falho ou restrito a uma parte da população por diversos fatores de ordem econômica, social, cultural, psicológica, legal, falta de conhecimento e a lentidão da justiça. Cada um desses fatores isolados é o suficiente para impossibilitar o contato de uma pessoa com o Poder Judiciário, em maior ou menor proporção. (NASCIMENTO, 2010, p. 2)

Levando em conta o potencial dos museus em contribuir para diminuir tal distanciamento e os avanços regulatórios na área, surgiu a curiosidade em investigar a aplicabilidade do Estatuto nos museus do âmbito do Poder Judiciário no Brasil, principalmente no que diz respeito às diretrizes de comunicação dessas instituições.

\section{Metodologia}

Para a realização da pesquisa, tomou-se como base as técnicas que John B. Thompson (1995) classificou como referencial metodológico da Hermenêutica de Profundidade (HP). O método já foi utilizado com êxito em outras produções ligadas à Comunicação, como em 2013, por Jairo Faria Coelho, que se propôs a analisar a efetividade da política pública de implementação de ouvidorias em canais privados de abrangência nacional da Colômbia. Assim como Luma Dutra , em 2015, que seguindo o mesmo referencial metodológico buscou compreender a utilização da Lei de Acesso à Informação por jornalistas como ferramenta de trabalho.

O método tem como principal proposta a interpretação de formas simbólicas, compreendidas por Thompson como produtos resultantes de fenômenos sociais. O caminho da interpretação, de acordo com a HP, contempla três eixos principais, que se articulam entre si e não precisam necessariamente ser desenvolvidos de forma sequenciada. São eles:a) análise sócio-histórica, cujo objetivo é reconstruir as condições sociais e históricas de produção, circulação e recepção das formas simbólicas; b) análise formal ou discursiva, na qual o termo discurso é utilizado por Thompson, de um modo geral, para se referir às diversas instâncias de comunicação, e a análise é feita com base nas características estruturais das relações dos discursos em questão; c) re-interpretação, compreendida como uma etapa de explicação interpretativa do pesquisador diante do que foi obtido, o termo re-interpretação se justifica por considerar que todas informações obtidas no caminho da pesquisa fazem parte de um campo pré- 
-interpretado pelos sujeitos que constituem o mundo sócio-histórico.

Thompson (2002) explica que estes três eixos não devem ser apresentados como um roteiro a ser seguido, mas como esferas de análises particulares que compõem um processo interpretativo. Pesquisadores como Paulino (2008) sistematizam a importância desta perspectiva:

\begin{abstract}
Thompson quer reagir à tendência da pesquisa clássica de reduzir tudo a objeto de análise formal. Ele assinala que os objetos de investigação social representam um território pré-interpretado. $\mathrm{O}$ mundo sócio-histórico não é apenas um campo-objeto, mas um campo-sujeito construído, em parte, por sujeitos preocupados em compreender a si mesmo e aos outros, em interpretar as ações, falas e acontecimentos que estão ao seu redor (PAULINO, 2008, p. 4I)
\end{abstract}

Nesse sentido, somente com o processo de interpretação é possível legitimar o caráter distintivo de cada campo-objeto. As formas simbólicas estão inseridas em contextos sociais e históricos de diferentes tipos, e por serem construções simbólicas significativas, estão estruturadas internamente de várias maneiras. Sendo assim, as formas simbólicas não podem ser analisadas separadamente dos contextos em que são produzidas e interpretadas.

Para o presente estudo, os três eixos de análise se articularam da seguinte forma: levantamento bibliográfico e documental, entrevistas semiestruturadas com atores chave relacionados aos tribunais estudados e re-interpretação dos dados obtidos. Os atores entrevistados foram:

I) Os gestores dos museus estudados. São eles:Ana Cristina Paes - Chefe da Seção de Memória Institucional do STF; Evanildo Carvalho - Chefe da Seção de Memória e Difusão Cultural do ST]; Rita Ferreira Porto - Supervisora do Museu do STM;Admilson Siqueira Junior - Chefe da Seção de Museu do TSE; e Reginaldo Pereira Matos - Supervisor do Memorial do TST.

2) Os assessores de comunicação dos tribunais. São eles: Elaine Almeida Rocha - Coordenadora de Imprensa do ST]; Roberto Thomaz - Coordenador de Imprensa do TSE; Patrícia Resende Nascimento - Secretária de Comunicação do TST.

3) A Museóloga Célia Corsino - uma das primeiras museólogas atuantes em Brasília, atualmente superintendente do Iphan de Minas Gerais. Trabalhou na criação de diversos museus institucionais em Brasília e prestou consultorias técnicas para quatro dos cinco museus estudados.

Os dados coletados que serão apresentados a seguir têm como objetivo oferecer ao leitor um panorama de aplicabilidade do Estatuto de Museus nas instituições de memória ligadas ao judiciário no Brasil, principalmente no que diz respeito às ações ligadas a comunicação. Trata-se de uma análise institucional em uma perspectiva ampla, sem qualquer intenção de colocar em risco ou de expor o profissional que se encontra a frente do museu em questão, por essa razão optou-se por assegurar a confidencialidade dos depoimentos utilizados durante a análise. 


\section{Estatuto de Museus e Comunicação}

Conforme pontuado anteriormente, o Estatuto de Museus, Lei I I.904/2009, estabelece que ações de comunicação constituem "formas de se fazer conhecer os bens culturais incorporados ou depositados no museu, de forma a propiciar o acesso público" (art. 31). Nesse sentido, foram delimitadas algumas diretrizes de análise, presentes na redação da Lei, que dizem respeito a ações de comunicação e de promoção do acesso público a esses espaços, com o objetivo de verificar se os museus dos tribunais superiores estão alinhados ou não a tais aspectos legais. As diretrizes selecionadas serão apresentadas abaixo, seguidas das informações re-interpretadas sobre a realidade dos museus, com base nas informações coletadas durante entrevistas com os atores ligados as instituições estudadas.

O primeiro artigo utilizado para análise, diz respeito a quais instituições estarão submetidas a lei, no qual estão contempladas "as instituições e os processos museológicos voltados para o trabalho com o patrimônio cultural e o território visando o desenvolvimento cultural e socioeconômico e a participação das comunidades” (art. I, parágrafo único).

Além de destacar o potencial das instituições museológicas de serem um instrumento de desenvolvimento cultural e socioeconômico, com a participação ativa da comunidade, o referido artigo chama atenção pela abrangência das instituições que estão contempladas na lei, independentemente de sua denominação.

Um dos principais aspectos observados durante as entrevistas realizadas foi o de que apesar dos cinco museus estarem registrados no Cadastro Nacional de Museus, de acordo com depoimento dos gestores, é possível verificar que a maioria dos espaços não se reconhece como um museu. Algo curioso, é que duas das cinco instituições estudadas, foram criadas com a denominação museu no organograma institucional, mas após o ano de 2009 , ano de criação do Estatuto de Museus, sofreram mudanças no organograma. Algo que denota uma possível tentativa dessas instituições se resguardarem de alguns parâmetros técnicos previstos pelo Estatuto, como por exemplo a exigência de museus estarem à serviço da sociedade, de implementação de um Plano Museológico e existência de um(a) Museólogo(a) na equipe. Conforme pontua uma das gestoras entrevistadas, ao relatar dificuldades de adequação à estrutura técnica de museu:

Eu senti que um dos motivos implícitos na mudança de denominação foi que como não tínhamos uma estrutura adequada, de repente nosso compromisso com o público externo não seria tão latente, mas isso é leitura minha. Eu acho que a partir de então as atividades se voltaram mais para dentro do tribunal. Acho que restringiu um pouco. (Informação verbal, 2018)

Em outro depoimento é possível verificar que:

A mudança foi vertical, vindo de cima para baixo. Nós ficamos sabendo só que saiu uma portaria com a mudança na época, não fomos consultados em nada. Eles fazem por sessão administrativa né? Eles reúnem os ministros, submetem o assunto e deliberam sobre aquilo. (Informação verbal, 2018) 
Diante disso, compreende-se que a questão da denominação das unidades de memória inseridas nos tribunais estudados não se caracteriza simplesmente de uma questão de organograma institucional, mas de uma possível tentativa de se isenção das responsabilidades técnicas de um museu. Porém, de acordo com o art. $1^{\circ}$ do Estatuto de Museus, o que caracteriza uma instituição como um museu não é sua denominação e sim suas atividades.

Consideram-se museus, para os efeitos desta Lei, as instituições sem fins lucrativos que conservam, investigam, comunicam, interpretam e expõem, para fins de preservação, estudo, pesquisa, educação, contemplação e turismo, conjuntos e coleções de valor histórico, artístico, científico, técnico ou de qualquer outra natureza cultural, abertas ao público, a serviço da sociedade e de seu desenvolvimento. (BRASIL, 2009)

Durante as entrevistas, ao informar os gestores sobre a questão pontuada acima, foi possível ouvir relatos como:

\begin{abstract}
Aí tem uma grande questão, porque tem uma turma que prefere que volte para museu, outra turma que prefere centro de documentação ou então memorial, então esses entendimentos ainda estão conflitantes por aqui. (Informação verbal, 2018)
\end{abstract}

Em contato com um outro gestor, a questão da denominação se apresentou de maneira ainda mais complexa. Foi possível perceber que há falta de conhecimento do próprio significado de museu. $\mathrm{Na}$ tentativa de justificar porque se consideram um memorial e não um museu, o gestor argumenta que:

\footnotetext{
Quando você fala de memorial você fala de uma coisa mais específica. Museu é uma coisa mais geralzão, entende? E um memorial é uma coisa mais focada em uma área. Você não vai ver a gente falando de todas as áreas do judiciário, por ser uma área só, somos um memorial. (Informação verbal, 20।8)
}

Apesar do memorial em questão também desenvolver todas as atividades de um museu, a justificativa para não se considerarem um museu é no sentido de que "pra ser museu, tem alguns requisitos que no memorial a gente não tem, como um plano museológico, um museólogo. Vários tópicos que um memorial não tem, a amplitude”. (Informação verbal) .

Das cinco instituições estudadas, duas se reconhecem enquanto museu. Um desses, inclusive, fez o movimento contrário ao citado anteriormente. Era considerado Espaço de Memória dentro do tribunal, mas após a criação do Estatuto, foi regulamentado como museu. A justificativa, segundo o gestor, é que por serem parte da Administração Federal tinham que tomar essa iniciativa, além da facilidade em firmar parceria com o lbram.

O segundo artigo da Lei aqui destacado, trata dos princípios fundamentais dos museus, são eles: "I - a valorização da dignidade humana; II - a promoção da cidadania; III - o cumprimento da função social; IV - a valorização e preservação do patrimônio cultural e ambiental; $\vee$ - a universalidade do acesso, o respeito e a valorização à diversidade cultural; $\mathrm{VI}$ - o intercâmbio institucional $\left(\operatorname{art} .2^{\circ}\right)$.

Considerando que a universalidade do acesso é considerada um dos princípios fundamentais previstos no Estatuto, buscou-se identificar quais as estratégias realizadas pelos museus dos tribunais para proporcionar o acesso, assim como identificar sua predominância de público. 
Uma característica em comum nos museus estudados é que a divulgação de suas atividades é realizada pelas assessorias de comunicação dos tribunais. Os museus não contam com profissionais de comunicação em suas equipes. As assessorias divulgam as atividades do museu como fazem com qualquer outro setor do tribunal. Durante a pesquisa, não foi encontrado um programa específico de comunicação nesses museus, conforme previsto pelo Estatuto de Museus (art. 46), por exemplo. As divulgações são feitas pelos sites institucionais, redes sociais, mala direta em alguns casos e periodicamente na TV e Rádio Justiça .

Diante dos dados coletados, percebeu-se que o fato de não possuírem profissional de comunicação na própria equipe do museu dificulta um trabalho de comunicação contínua. Os assessores entrevistados informaram que fazem as divulgações do museu sempre de acordo com novas atividades. Ou seja, se não houver o gancho jornalístico de alguma novidade, não há divulgação, conforme pontuado por uma das comunicadoras entrevistadas para justificar a falta de divulgações mais frequentes. Sem novas exposições, eventos, inaugurações, lançamentos, não há iniciativa de falar sobre o museu. Verificou-se necessário, então, a existência de um plano de divulgação contínua desses museus, ainda que seja apenas referente a divulgação de suas exposições permanentes.

O art. 17 do Estatuto de Museus trata de outra questão essencial para que seja possível planejar e executar projetos dentro de uma instituição museológica, considerando seu quadro de pessoal.A Lei prevê que "a entidade gestora do museu público garantirá a disponibilidade de funcionários qualificados e em número suficiente para o cumprimento de suas finalidades" (art. 17, parágrafo único).

Uma das principais justificativas ouvidas por alguns gestores para a falta de atividades mais amplas de difusão do museu que atuam, foi a de que o quadro de funcionários é restrito.

Para que se possa ter uma ideia de como o quadro de pessoal pode refletir nas ações de comunicação, entre os cinco museus analisados, há um que se destaca, pelo seu quantitativo de visitantes anual ser em média de quinze mil, enquanto os outros possuem uma média de apenas mil ao ano. Esse museu em destaque possui dezessete funcionários, considerando toda a coordenação de memória da qual faz parte. Já um outro museu, possui somente dois servidores em seu quadro. O gestor desta instituição museológica relata que:" Já teve momentos de ter I pessoa só trabalhando dentro do museu, essa pessoa fez o meIhor possível. Louvo o esforço que foi feito pela pessoa que me antecedeu, mas dentro das possibilidades não conseguiu processar todo acervo, por exemplo." (Informação verbal, 20I8)

Em outra instituição, o gestor relata um panorama semelhante, ao dizer que "nossa equipe ainda é muito pequena, a gente se vê apagando incêndio o tempo todo, fazemos o que dá pra fazer" (Informação verbal).

Outra questão fundamental para a aproximação entre os museus e a sociedade é a utilização do potencial educativo dessas instituições, conforme descrito na lei "os museus deverão promover ações educativas, fundamentadas no respeito à diversidade cultural e na participação comunitária, contribuindo para ampliar o acesso da sociedade às manifestações culturais e ao patrimônio material e imaterial da Nação" (art. 29).

Somente dois dos museus estudados possuem um programa educativo estruturado, o que reflete significativamente no quantitativo anual de visitantes. Nessas instituições, o programa educativo é considerado pelos gestores uma importante ferramenta de comunicação com o público. $\bigcirc$ tribunal oferece 
transporte, alimentação para estudantes de escolas públicas, com uma programação didática voltada para o fortalecimento da imagem institucional na sociedade.

Porém, ainda nessas instituições com práticas mais desenvolvidas nesse aspecto, os gestores consideram que por não fazerem parte da atividade fim da instituição, correm risco constante de sofrerem cortes. Um dos gestores informa que já passaram por "altos e baixos", já perderam ônibus, lanche e em seguida ganharam novamente, depende muito da visão da alta gestão em exercício.

No que diz respeito à composição de público dos museus em questão, considerando que de acordo com a lei "os museus caracterizar-se-ão pela acessibilidade universal dos diferentes públicos, na forma da legislação vigente” (art. 35), pode-se dizer que ainda é necessário desenvolver estratégias para atrair perfis mais plurais de visitantes. A predominância de público que visita os museus dos tribunais é de servidores, autoridades e estudantes de diferentes faixas etárias, por meio de ações educativas que a maioria desempenha.

Tratam-se geralmente de visitas ao tribunal todo, não somente ao museu, agendadas pelo serviço de Cerimonial de cada tribunal. Este cenário dificulta identificar o interesse de acesso ao museu por si, pois o museu não se apresenta em primeiro plano nas visitas, faz parte de um roteiro amplo de visitação a todo tribunal.

No que diz respeito a verificação da existência ou não de um Plano Museológico nos museus estudados, partimos do princípio de que "é dever dos museus elaborar e implementar o Plano Museológico" (art. 44), compreendido como ferramenta básica de planejamento estratégico, fundamental para a sistematização do trabalho interno e para a atuação dos museus na sociedade, com identificação dos públicos a quem se destina o trabalho dos museus, com onze programas, um específico para cada setor, incluindo de Comunicação (art. 45 e 46).

Em dois dos tribunais estudados ocorreu tentativa de adequação ao Estatuto por meio da criação de documento de planejamento institucional compreendido pelas respectivas equipes como um "Plano Museológico", porém em desconformidade com alguns parâmetros técnicos, como por exemplo, o fato de não terem sido elaborados por um profissional museólogo. Em três outros tribunais, não foi identificada durante esta pesquisa a existência de Plano Museológico.

A dinâmica administrativa dos tribunais foi citada por todos os gestores entrevistados como um fator de risco ao planejamento e execução de ações em longo prazo. Com a mudança constante de gestão a cada dois anos, torna-se difícil desenvolver ações mais aprofundadas. Essa realidade faz com o que os museus dos tribunais trabalhem sob demandas não programadas, como por exemplo, montagens de exposições temporárias sem elaboração de projeto prévio que esteja alinhado à missão da instituição, de acordo apenas com solicitações da alta gestão.

Ainda em relação a estrutura do tribunal em que estes museus estão inseridos, foi possível identificar que existem facilidades e dificuldades na relação entre os diversos setores do tribunal. $O$ fato de não poder contar com áreas específicas para o museu, coloca estes como qualquer outro setor dentro do tribunal, o que oferece risco à integridade do acervo, por exemplo, por não terem um programa de segurança próprio, com maior disponibilidade de vigilância para as galerias e espaços de reserva técnica. 
Apesar de o art. 67 do Estatuto ter previsto o prazo de adequação de dois anos para os museus federais e cinco anos para os demais museus (art. 67) às normas estabelecidas, em um dos museus estudados houve um movimento imediato de recolhimento após a criação da lei, por meio de ato administrativo do Tribunal, como mencionado anteriormente. Esta ação realizada pela Corte em questão demonstra uma indisposição de tentativa de adequação à lei dentro do período previsto.

Em complemento ao que foi apresentado acima, é possível sintetizar algumas informações básicas sobre os cinco museus dos tribunais superiores, no que diz respeito a alguns aspectos da Lei II.904/2009, conforme pode ser visualizado na tabela a seguir:

\begin{tabular}{|l|l|}
\hline Tem conhecimento da existência do Estatuto de Museus? & Todos \\
\hline São registrados no Cadastro Nacional de Museus? & Todos \\
\hline Possuem documento de criação? & Apenas dois \\
\hline Possuem Plano Museológico? & $\begin{array}{l}\text { Apenas dois, mas ambos fora dos parâmetros técnicos do } \\
\text { Estatuto de Museus. }\end{array}$ \\
\hline Encontram-se abertos para visitação? & Todos \\
\hline Promovem ações educativas? & Três deles \\
\hline Fazem levantamento de visitantes? & Quatro deles possuem dados quantitativos de público \\
\hline Qual predominância de público? & Servidores, autoridades da Corte e estudantes \\
\hline Possuem algum método de auto-avaliação? & Dois deles realizam ações de devolutiva dos visitantes \\
\hline
\end{tabular}

Fonte: elaboração própria.

Diante dos dados expostos, torna-se possível o entendimento de que a criação do Estatuto de Museus gerou certo movimento regressivo em alguns museus do Poder Judiciário, na tentativa de se resguardarem das diretrizes da lei, apresentam resistência até mesmo para se reconhecerem como um museu. Esse contexto pode ser relacionado com o que no âmbito do Direito Regulatório é conhecido como creative compliance.

De acordo com Morgan e Yeung (2007, p. 164-165) creative compliance é uma atividade que ocorre quando o regulado se vale da literalidade de alguma regra regulatória para, sustentando seu cumprimento, evitar o alcance do objetivo que tal regra persegue. $O$ regulado interpreta a regra de forma literal, sem levar em consideração seu real propósito. Ou seja, tendo sido criado um Estatuto Museus, bastaria deixar de se denominar um museu para não seguir suas diretrizes?

Nesse sentido, pode-se dizer que tal movimento gera um recolhimento no setor, considerando o passo regressivo de alguns museus institucionais, resultante de ações verticais de seu órgão mantenedor, por receio aos parâmetros técnicos previstos na lei. Nos museus estudados que menos se adequaram ao Estatuto é possível perceber que estes atuam mais como um espaço cerimonial do que de promoção do direito às informações públicas.

\section{Conclusões}

A partir das observações realizadas, surgiram alguns questionamentos como: por que apesar da dificuldade de adequação às normas técnicas, tribunais optam por criar e manter museus em suas estruturas? A que se deve o interesse dessas instituições em criar um museu? Não haveria outras estratégias capazes de divulgar a trajetória institucional? As assessorias de comunicação teriam con- 
dições de desenvolver essa missão sem a necessidade de museus?

A intenção para o presente artigo não foi de necessariamente responder completamente a esses questionamentos, mas oferecer subsídios para um exercício de reflexão sobre a realidade museológica vivenciada em Brasília, cujos museus institucionais representam quantitativo expressivo. Por se tratarem de instituições públicas, a curiosidade em compreender se esses espaços utilizam diretrizes previstas na legislação se tornou ainda mais latente.

Diante da dificuldade verificada de o Estatuto de Museus ser cumprido, foi possível concluir que a lei por si só não é suficiente, embora em vigor há nove anos, apenas a norma, sem uma fiscalização eficiente, dificilmente será cumprida. Nesse sentido cabe questionar, se nem mesmo os tribunais superiores estão cumprindo a lei no desenvolvimento de suas atividades museológicas, o que esperar de outros museus?

Verifica-se assim, a possibilidade desse tipo de aplicação metodológica ser utilizada em outros estudos no Brasil, buscando compreender a realidade dos atores que compõem os espaços museológicos, para que este marco regulatório que é o Estatuto de Museus possa, de fato, contribuir para diminuir o distanciamento ainda acentuado entre museus e sociedade.

\section{Referências}

BRASIL. Câmara Legislativa. Legislação sobre museus. Brasília: Edições Câmara, 2012. 157 p. (Série Legislação; n. 79).

CHAGAS, Mário de Souza e NASCIMENTO JUNIOR, José do (organizadores). Subsídios para a criação de Museus Municipais. Rio de Janeiro, RJ: Ministério da Cultura/Instituto Brasileiro de Museus e Centros Culturais/Departamento de Processos Museais, 2009.

COELHO, Jairo Faria Guedes. Ouvidoria na TV: a experiência dos canais privados colombianos. 20I3. 193 f. Dissertação (Mestrado em Comunicação)—Universidade de Brasília, Brasília, 2013. Disponível em: < http://repositorio.unb.br/ bitstream/ I 0482/ / 3338/ I/20 I3_JairoFariaGuedesCoelho.pdf>Acesso em $6 \mathrm{dez}$. 2018.

CURY, Marilia Xavier. O campo de atuação da museologia. In: Exposição: concepção, montagem e avaliação. São Paulo:Annablume, 2005.

DUTRA, Luma Poletti. Direito à informação em pauta: os usos da lei de acesso por jornalistas. 20I5. I 48 f., il. Dissertação (Mestrado em Comunicação)—Universidade de Brasília, Brasília, 2015. Disponível em: < http://repositorio.unb.br/ bitstream/I0482/I7909/2/20I5_LumaPolettiDutra.pdf> Acesso em 5 dez. 20 I8.

FERNANDES, José Ricardo Oriá. O Direito à Memória:A Museologia brasileira e seu novo marco regulatório. In: II Encontro Internacional de Direitos Culturais. Fortaleza, 2013.

INSTITUTO BRASILEIRO DE MUSEUS (IBRAM). Relatório final da pesquisa do "não-público" dos museus: levantamento estatístico sobre o "não ir" a museus no Distrito Federal. CPIM/DEPMUS/IBRAM, 2012. 
JULIÃO, Leticia. Apontamentos para a história do museu. Caderno de Diretrizes Museológicas. Brasília: Ministério da Cultura/Belo Horizonte: Secretaria de Estado de Cultura, 2006.

KOPTKE, Luciana Sepulveda. Analisando a dinâmica da relação Museu-educação formal. In: FUNDAÇÃO OSWALDO CRUZ (FIOCRUZ). Casa de Oswado Cruz (COC). Museu da Vida. Caderno do Museu daVida: o formal e o não-formal na dimensão educativa do museu:200I/2002. Rio de Janeiro.

MAGALDI, Monique Batista. Navegando no museu virtual: um olhar sobre formas criativas de manifestação do fenômeno museu. 2010. 209 f. Dissertação (Mestrado em Museologia e Patrimônio) - Museu de Astronomia e Ciências Afins, Universidade Federal do Estado do Rio de Janeiro, 2010.

MORGAN, Bronwen and YEUNG, Karen. An Introduction to Law and Regulation. Text and Materials. Cambridge University Press, New York, 2007.

NASCIMENTO, Meirilane Santana. Acesso à Justiça: Abismo, população e Judiciário. In: Âmbito Jurídico, Rio Grande, XIII, n. 74, mar 20I0. Disponível em: <http://www.ambito-juridico.com.br/site/index.php?n_link=revista_artigos_ leitura\&artigo_id=7498>.Acesso em $5 \mathrm{dez} 2018$.

NOGUEIRA, Daniele Galvão Pestana. A preservação da memória do Tribunal de Contas da União por meio de seu museu. Dissertação de Mestrado em Ciência da Informação. Faculdade de Ciência da Informação. Universidade de Brasília, 20 I5.

PAULINO, Fernando Oliveira. Responsabilidade social da mídia: análise conceitual e perspectivas de aplicação no Brasil, Portugal e Espanha. 2008. 357 f. Tese (Doutorado em Comunicação) - Faculdade de Comunicação, Universidade de Brasília, Brasília. Disponível em: < http://repositorio.unb.br/bitstream//0482/5 I75/l/ Tese_Fernando\%20\%20Paulino.pdf> Acesso em 6 dez. 2018

THOMPSON, John B. Ideologia e Cultura Moderna:Teoria Social Crítica na Era dos Meios de Comunicação de Massa. Petrópolis, RJ:Vozes, 1995. 